\title{
First report of summer canker caused by Pectobacterium carotovorum subsp. actinidiae on kiwifruit in Jiangxi, eastern China
}

\author{
MingFeng Yan ${ }^{1} \cdot$ Bing Liu $^{1} \cdot$ ManFei Zou ${ }^{1} \cdot$ Ying Zhou $^{1} \cdot$ JunXi Jiang ${ }^{1}$ \\ Received: 3 September 2018 / Accepted: 2 February 2019 / Published online: 21 February 2019 \\ (C) Società Italiana di Patologia Vegetale (S.I.Pa.V.) 2019
}

Keywords Kiwifruit · Summer canker · Pectobacterium carotovorum subsp. actinidiae · Eastern China

Bacterial canker-like symptoms on yellow kiwifruit (Actinidia chinensis cv. Hort16A) were observed in Fengxin county of Jiangxi province, eastern China with an incidence of approximately 10\% (percentage of plant affected) in July 2018. The symptoms were characterised by cankers with reddish exudation on twigs and stems, closely resembling those caused by Pseudomonas syringae pv. actinidiae. However, the new disease occurs in the hot summer instead of early spring, and results in rapid wilting and death of the entire plant. The obtained 28 isolates in lysogeny broth medium from infected stem tissues were gram-negative, rod-shaped, facultative anaerobic, able to hydrolyze casein and gelatin, but not starch and Tween 80 . They could cause hypersensitivity in tobacco, and grow well at $37^{\circ} \mathrm{C}$. The $16 \mathrm{~S}$ rDNA region of a representative isolate (SKY-1) was sequenced (GenBank accession No. MH753595) and it showed 99\% identity with Pectobacterium carotovorum subsp. actinidiae (Pca) (KY307837 and NR125539). PCR detection of Pca with specific primers PcaF/PcaR (Lee et al. 2015) was positive and the sequence (MH766659) shared 99\% identity with the corresponding sequences in GenBank (KY315740 and FJ969378). Stems of kiwifruit plants (cv. Hort16A) from the field were inoculated by injecting $30 \mu \mathrm{l}$ of a bacterial suspension $\left(1 \times 10^{7} \mathrm{CFU} / \mathrm{ml}\right)$, while control stems were inoculated with sterilized water. All the tested samples were kept in a moist chamber at $33^{\circ} \mathrm{C}$. After 7 to 8 days, typical symptoms similar to those in the field appeared on the inoculated stems, whereas the control stems remained symptomless. Pca was successfully re-isolated from symptomatic stems. $P c a$ was previously observed in Korea and Sichuan province of southwest China (Koha et al. 2012; Wu et al. 2017). To our knowledge, this is the first report of Pectobacterium carotovorum subsp. actinidiae causing disease on kiwifruit in Jiangxi province, eastern China.

Funding This study was supported by the National Natural Science Foundation of China (Grant No. 31460452).

Publisher's note Springer Nature remains neutral with regard to jurisdictional claims in published maps and institutional affiliations.

\section{References}

Koha YJ, Kima GH, Leeb YS, Sohnb SH, Kohb HS, Kwonc S, Heud S, Jungb JS (2012) Pectobacterium carotovorum subsp. actinidiae subsp. nov., a new bacterial pathogen causing canker-like symptoms in yellow kiwifruit, Actinidia chinensis. N Z J Crop Hortic Sci 40: 269-279

Lee YS, Jung JS, Kim GH, Koh YJ (2015) Detection of Pectobacterium carotovorum subsp. actinidiae, a bacterial pathogen in yellow kiwifruit Actinidia chinensis, by PCR. ISHS ActaHort (1096):397-402

Wu WX, Liu Y, Huang XQ, Zhang L (2017) First report of summer canker caused by Pectobacterium carotovorum subsp. actinidiae on kiwifruit in China's Sichuan Province. Plant Dis 101:1540

JunXi Jiang

jxau2011@126.com

1 College of Agronomy, Jiangxi Agricultural University,

Nanchang 330045, China 